\title{
Avocado Firmness Monitoring with Values Obtained by Means of Laser Doppler Vibrometry
}

\author{
S. Landahl and L.A. Terry \\ Plant Science Laboratory \\ Cranfield University \\ Cranfield, Bedfordshire MK43 0AL \\ United Kingdom
}

Keywords: Persea americana 'Hass', resonant frequency, non-destructive, ripeness

\begin{abstract}
Avocado (Persea americana Mill.) ripeness is usually evaluated by destructive firmness assessment, yet quality is notorious for being heterogeneous within a consignment. This problem, which is especially true for imported avocado fruit, lends itself to searching for non-destructive methods for firmness evaluation. Firmness of objects can be analysed by impulse-response. This technique utilizes recording of a vibration signature and interpretation of the resonant frequency. In this study a laser Doppler vibrometer (LDV) was used for non-contact recording. The aim of this study was to show the feasibility of using a LDV to monitor avocado firmness.

In order to create avocado batches of different homogeneity, three groups were treated with and without ethylene, inside or outside a box. After day 0 a third of the fruit were transferred into boxes $(325 \mathrm{~L})$ to be treated with ethylene for $24 \mathrm{~h}$. A third was kept in boxes untreated and another third was kept on open trays. Avocado fruit cultivar 'Hass' were ripened at $18^{\circ} \mathrm{C}$ and measured on days $0,2,3,4$ and 6. Individual fruit were impacted once and two LDV measurements were taken simultaneously at the stem-end and seed-end. This was repeated twice around the fruit. Force-deformation measurements in compression mode were performed by means of uniaxial testing (Instron model 5542) on two opposite sides (day $0 \mathrm{n}=8$, then $n=24$ i.e., 8 per treatment/d). Significant differences were found between firmness of avocados over time and across treatments. Firmness decreased exponentially as expected (304.1 to $2.1 \mathrm{~N})$ over six days. The LDV results showed significant differences between days, treatments and laser-location. The resonant frequency of the fruit decreased linearly until day $\mathbf{4}$ and then decreased more slowly $(1671$ to $476 \mathrm{~Hz})$. On average, the frequency found at the seed-end of the fruit was higher than the resonant frequency at the stem-end. This is thought to be due to the seed itself, which could influence the vibration pattern. Resonant frequencies showed good correlation to the logarithm of firmness $(r=0.87)$ and therefore were shown capable of monitoring avocado firmness.
\end{abstract}

\section{INTRODUCTION}

Avocado (Persea americana Mill.) fruit are an attractive addition to the diet due to their unique flavour and texture. In addition, avocados have reported health benefits (Ashton et al., 2006; Ding et al., 2007; Henrotin, 2008), as research has shown that eating avocado fruit flesh may contribute to lowering cholesterol levels (Ledesma et al., 1996). Avocado mesocarp tissue has high concentrations of desired nutrients such as unsaturated fatty acids and seven carbon carbohydrates.

The OECD (2004) recommends that the quality of avocado fruit can be rated according to size, estimated oil content (dry matter), absence of defects and fruit firmness. The degree of ripeness of many climacteric fruits like avocado can be correlated with fruit firmness. It has been shown that fruit often do not soften uniformly due to physiological gradients (Landahl et al., 2009).

Fruit and vegetables are qualitatively evaluated by organoleptic properties. Firmness is an important textural characteristic. Standard firmness evaluation is 
destructive and often subjective. In the past many studies have reported on attempts to predict firmness by non-destructive techniques (Ruiz Altisent et al., 2010). From as far back as the 1960s (Abbott et al., 1968) researchers have investigated the possibility of predicting firmness by impulse response (vibration) measurements. The recording of vibration signatures can be done by accelerometer or more recently by piezoelectric film (Lu et al., 2008), or non-contact by either microphone (Roth et al., 2007, 2008; Lu et al., 2008; Molina-Delgado et al., 2009) or by laser Doppler vibrometer (Blahovec et al., 2008; Tanawaki et al., 2010; Landahl et al., unpublished). The impulse response techniques are greatly influenced by angle and location of impact (Sun et al., 2010).

A laser-Doppler vibrometer (LDV) is a precision optical instrument used for determining vibration at a defined point (Polytec UK Ltd., 2011). The technology is based on the Doppler-effect; sensing the frequency shift of back scattered light from a moving surface. The Laser-Doppler vibrometer works on the basis of optical interference, requiring two coherent light beams, with their respective light intensities I1 and I2, to overlap; the resulting intensity is not just the sum of the single intensities, but is modulated. According to interference theory the overall intensity of two beams is zero if they have a path length difference of half of one wavelength. Changing the optical path length per unit of time manifests itself as the Doppler frequency shift, so that the modulation frequency of the interferometer pattern is directly proportional to the velocity of the object. However, the velocity of the object cannot indicate the direction it is moving in; for this purpose, an acousto-optic modulator (Bragg cell) is placed in the reference beam; This means that it is now possible not only to detect the amplitude of movement but also to clearly define the direction of movement. In principle the LDV can directly measure displacement as well as velocity. In this case, the frequency is not analysed, instead the LDV counts the bright-dark fringes on the detector. Displacement measurement is better suited for low frequency measurements.

The present study aimed to minimise the heterogeneity of a batch, which often occurs due to different agricultural practise, climate, season and duration of avocado transit by measuring all fruit non-destructively and sorting them according to the results. A feasibility study was conducted to test non-destructive laser Doppler vibrometry as an assessment tool for firmness in avocado fruit.

\section{MATERIALS AND METHODS}

\section{Plant Material}

All imported avocado fruit (Malaga, Spain) were supplied by M.W. Mack Ltd. (Kent, UK) and were transferred to a $6^{\circ} \mathrm{C}$ cool room immediately after delivery ( 8 boxes of size code 18 avocado fruit cultivar 'Hass'). Fruit from Spain arrived in the UK within a week after picking and a cool chain was applied of $5-6^{\circ} \mathrm{C}$. On day 0 (baseline) fruit were randomised and labelled and allowed to warm up to room temperature. Then tests were performed on 8 fruit. Forty fruit were transferred into gas tight boxes (ca. $325 \mathrm{~L}$ ) to be treated with ethylene for $24 \mathrm{~h}$ in a separate $18^{\circ} \mathrm{C}$ room. Fruit were not treated with 1-methylcyclopropene. Controlled ripening was initiated using exogenous ethylene (100 $\mu \mathrm{L} \mathrm{L}^{-1}$; BOC Gases Ltd., Surrey, UK; Terry et al., 2007b). Forty fruit were kept in boxes untreated and another 40 were kept on open trays in a temperature controlled $18^{\circ} \mathrm{C}$ room. All fruit were ripened at $18^{\circ} \mathrm{C}$ for 6 days. Tests were performed in a sequence. First non-destructive laser Doppler vibrometry (LDV) was performed, then firmness was measured destructively on two opposite sides of the fruit and last mesocarp tissue was snap frozen in liquid nitrogen for sugar analyses (thin slice cut across longitudinal axis of fruit). During ripening 8 fruit were measured per treatment each on days 2, 3, 4 and 6 $(\mathrm{n}=8+4 \times 24=104)$. Frozen samples of fruit tested on days $0,2,3$ and 6 were analysed for sugar content $(\mathrm{n}=80)$.

\section{Textural Evaluation}

Avocado fruit firmness was measured on opposite sides of peeled fruit. All texture 
tests were performed on a uni-axial testing machine (model 5542, Instron, MA) equipped with calibrated $500 \mathrm{~N}$ load cell. The machine was programmed (Bluehill 2, version 2.11, Instron) such that the probe indented the sample to a depth of $8 \mathrm{~mm}$ with the cross head speed set at $20 \mathrm{~mm} \mathrm{~min}^{-1}$. A flat cylinder probe of $8 \mathrm{~mm}$ diameter was used. The mean value of two replicate measurements was calculated for each fruit. Firmness was expressed as the force required for tissue failure (N) as detected in the force-deformation curve, maximum force (lbf) as commonly used by industry in the UK and the slope of the force-deformation curve $\left(\mathrm{N} \mathrm{mm}^{-1}\right)$ were recorded.

Non-destructive measurements were done simultaneously with two LDV (CLV 1700 and CLV 2534, Polytec UK Ltd., UK). The fruit were impacted once and two measurements were taken at different spots on the fruit (stem-end and seed-end). During the experiment avocados were manually impacted with a self-fabricated little hammer consisting of a cable tie and a nylon ball (1 cm diameter) and data recorded in a customised Labview program (v. 9.0, National Instruments Corporation, Austin, TX). Sampling frequency was $40 \mathrm{kHz}$. The fruit were impacted at 3 different spots around the equator. Three signal-pairs $(10 \mathrm{~ms}$ each $)$ of each fruit were saved and processed resulting in two results for each fruit (one per laser). Resonant frequencies were calculated using Matlab software (7.0.4.365 R14 Service Pack 2, The MathWorks Inc., MA).

\section{Non-Structural Carbohydrates Extraction and Quantification}

Frozen mesocarp tissue samples of the slices were freeze-dried in a Christ freeze dryer with cooling trap ALPHA (100 400, Osterode, Germany) for 7 days at $0.05 \mathrm{hPa}$ (Terry et al., 2007a). Dry mass (DM) was recorded and samples returned to $-40^{\circ} \mathrm{C}$ until further processing. Lyophilized mesocarp tissue was ground, weighed (to $1 \mathrm{~g}$ ) and a hexane extraction performed as described by Meyer and Terry (2008). The recovered powder was weighed and returned to $-40^{\circ} \mathrm{C}$ for subsequent non-structural carbohydrate (NSC) analysis.

NSCs were extracted and quantified as previously described (Terry et al., 2007a) with some modification according to Meyer and Terry (2008). Starch was not analysed. Mixed standards of known composition and concentration were used and presence of each NSC quantified by comparing sample peak areas to the standards.

\section{Ethylene and Carbon Dioxide Quantification}

Two avocados each were held in $3 \mathrm{~L}$ jars for 3 hours. Gas samples were removed with repeated full withdrawal-injection displacements of a $50 \mathrm{ml}$ plastic syringe (Terry et al., 2007b). Ethylene concentration was quantified using a GC8340 gas chromatograph (Carlo Erba Instruments, Herts., UK) fitted with an EL 980 FID and DP800 integrator (Thermoquest, Herts., UK). Oven and detector temperatures were set at $100^{\circ} \mathrm{C}$. The $2 \mathrm{~m}$ long stainless steel column was packed with Porapak (Jones Chromatography, Mid Glamorgan, UK). Ethylene was calibrated against $10.6 \mu \mathrm{l} \mathrm{L}^{-1}$ ethylene balanced in $\mathrm{N}_{2}$ (British Oxygen Company (BOC) Gases, Surrey, UK). $\mathrm{CO}_{2}$ was quantified using the same GC system with hot wire detection. The hot wire detector was operated at $120^{\circ} \mathrm{C}$ and the oven at $50^{\circ} \mathrm{C}$. The $\mathrm{GC}$ was calibrated with $10.06 \%(\mathrm{v} / \mathrm{v}) \mathrm{CO}_{2}$ in $\mathrm{N}_{2}(\mathrm{BOC})$.

\section{Statistical Analyses}

ANOVA was carried out using Genstat for Windows, version 9.1.0.147 (VSN International Ltd., Hertz., UK). Chemometric analyses were carried out using The Unscrambler (9.8, Camo Software Inc., NJ). Partial least squares regression (PLS) was performed. Data were centred and variables were weighted. Total explained variance, loading plots and score plots were used for interpretation.

\section{RESULTS AND DISCUSSION}

\section{Textural Evaluation}

The statistical analysis by ANOVA detected significant differences between the 
groups of avocados measured by means of uniaxial testing machine on different days and in different treatments. The force at breakpoint (N), max. load (lbf) and slope of forcedeformation curve $\left(\mathrm{N} \mathrm{mm}^{-1}\right)$ decreased exponentially during time (on average: 231.12.1 N, 50-0.6 lbf, 66.4-2.9 $\mathrm{N} \mathrm{mm}^{-1}$, respectively) as expected. In all cases the decrease was slightly slower at the beginning for fruit held in an open tray compared to those held in a box with or without exogenous ethylene treatment.

As reported previously, physical and biochemical changes occur heterogeneously within the avocado fruit during ripening (Landahl et al., 2009), which contributes to variability of test results. The max. load remains the main commercial indicator for ripeness, which was confirmed during an internal taste panel trial conducted during the course of the project (data not shown). It was revealed that fruit with max. load between 1 and $7 \mathrm{lbf}$ were the most desirable. Therefore, in this study the common commercial values were used as reference, keeping in mind that the force at breakpoint in SI units was closely related to these values.

\section{Non-Structural Carbohydrates}

The sucrose content per solid dry matter fraction increased slightly (on average: 7.57-9.44 mg/g DM) and mannoheptulose and perseitol decreased (on average: 16.34$3.12 \mathrm{mg} / \mathrm{g}$ DM and 20.22-6.18 mg/g DM, respectively). This is in accordance with values found previously (Landahl et al., 2009). Mannoheptulose and its sugar alcohol perseitol are 7-carbon carbohydrates with health benefits. Liu et al. (2002) suggested a role of mannoheptulose as a ripening inhibiting factor. It was suggested that past a certain threshold value ripening occurs in avocado fruit. Therefore, it was expected that mannoheptulose concentration decreases as fruit soften.

\section{Ethylene and Carbon Dioxide}

As expected a peak of respiration and ethylene production was found during the initial stages of ripening $\left(\mathrm{CO}_{2}\right.$ day 0 on average: $0.7 \%(\mathrm{v} / \mathrm{v})$, day 2 and $3: 2.6 \%(\mathrm{v} / \mathrm{v})$, day 4: $2.3 \%(\mathrm{v} / \mathrm{v})$. Ethylene day 0 on average: $2.2 \mu \mathrm{L}^{-1}$, day 2 and $3: 25.0 \mu \mathrm{L}^{-1}$, day 4 : $\left.10.5 \mu \mathrm{L}^{-1}\right)$. Both peaks were highest from fruit kept in a gas-tight box without ethylene treatment. This agrees with the finding of firmer fruit kept on an open tray and the observation re-occurred in the resonant frequencies.

\section{Resonant Frequency}

The resonant frequency of the fruit decreased linearly until day 4 and decreased more slowly thereafter (on average day $0: 1643 \mathrm{~Hz}$, day 2: $1199 \mathrm{~Hz}$, day 3: $932 \mathrm{~Hz}$, day 4: $680 \mathrm{~Hz}$, day 6: $541 \mathrm{~Hz}$ ). Throughout the experiment the fruit held in a box but not treated with ethylene exogenously showed the lowest frequencies, which was surprising, since either the fruit on an open tray with lower moisture content or the ethylene treated fruit were thought to soften quickest. Possibly the elasticity of the fruit on an open tray was actually higher than those fruit due to a tightened skin from increased moisture loss.

On average, the frequency found at the seed-end of the fruit was higher than the resonant frequency at the stem-end. This is in contrast with a study where firmer mesocarp tissue was found in the apical region of avocado fruit (Landahl et al., 2009). In that study mesocarp tissue was measured separate from the seed. In the future, the influence of the avocado shape on its vibration patterns needs to be studied in more detail.

Multivariate analysis of the data should help to calibrate and predict the firmness of the avocados online. Partial least squares regression (PLS) was performed to predict max. load. Due to statistical restriction the max. load values had to be transformed and the logarithm to the base of 10 was chosen. Either sugar concentrations and moisture content alone or with resonant frequencies of lasers positioned at the seed and stem end of the fruit were used to build a model to predict the log max. load. The calibration with destructively measured parameters alone showed an explained variance of $68 \%$ for $\log$ max. load in the first latent variable and $84 \%$ with the resonant frequencies included, respectively. This shows the importance of the non-destructively measured variables to 
predict firmness. Resonant frequency depends on mass, so that it is essential to measure batches, which are already graded for size, or to measure mass of the fruit online. Values of ca. $\mathrm{R}^{2}=0.76$ were found, when the resonant frequencies alone were correlated with the log max. load (Fig. 1). On the basis of this value, the performance of the LDV system was compared to existing technology available to industry. Tests showed that the Sinclair $\mathrm{IQ}^{\mathrm{TM}}$ Firmness Tester has a medium success rate in predicting Magness-Taylor (MT) values of 'Hass' avocados (Pearson correlation coefficient 0.05 significance): "The impact method was stronger correlated to the destructive elasticity modulus, sensory panellists and cone penetration $(\mathrm{r}=0.90,0.87$ and 0.83 , respectively) than to the MT $(\mathrm{r}=0.67)$ " (Howarth et al., 2003). Arpaia (2007) compared the Aweta AFS ${ }^{\mathrm{TM}}$ with penetrometer measurements. The general principle of impacting the fruit and then recording the vibration signal with a sensor is very similar to the LDV technique. Arpaia found that the impact readings are sensitive to changes in softer fruit, which is beneficial for measuring avocados for the "ready to eat" market, and reported that there was a significant change in the tissue strength properties of avocado measured by means of the Aweta AFS ${ }^{\mathrm{TM}}$ between 3 and $4 \mathrm{lbf}$ penetrometer firmness. This sharp change was not observed in the current study, and the relationship was not linear but closer to an exponential. As mentioned before the desired firmness in the UK for "ready to eat" avocados is 1 to $7 \mathrm{lbf}$, so problems to detect fruit with a firmness between 4 and $7 \mathrm{lbf}$ would be detrimental to choosing the Aweta AFS ${ }^{\mathrm{TM}}$ as an online sensor. These results indicate the LDV may be better suited to measuring avocado firmness.

\section{CONCLUSION}

The LDV technique has been shown to outperform existing instrumentation.

\section{ACKNOWLEDGEMENTS}

This work formed part of a larger FoodLink project (AFM 235) and was financially supported by the UK Government (Department for Environment, Food and Rural Affairs, Defra) and UK industry representatives (Lambda Photometrics Ltd., M.W. Mack Ltd., Marks and Spencer plc, Unilever R\&D). Support of Manuela Donetti, Cranfield University, is gratefully acknowledged. The support from Prof. George Jeronimidis, University of Reading, is greatly appreciated.

\section{Literature Cited}

Abbott, J.A., Bachman, G.S., Childers, R.F., Fitzgerald, J.V. and Matusik, F.J. 1968. Sonic techniques for measuring texture of fruits and vegetables. Food Technol. 22:101-112.

Arpaia, M.L. 2007. Avocado Postharvest Quality. In: Best Management Practices, Food Safety \& Post Harvest, Production Research Report. California Avocado Commission.

Ashton, O.B.O., Wong, M., McGhie, T.K., Vather, R., Wang, Y., Requejo-Jackman, C., Ramankutty, P. and Woolf, A.B. 2006. Pigments in avocado tissue oil. J. Agric. Food Chem. 54:10151-10158.

Blahovec, J., Kuroki, S. and Sakurai, N. 2008. Precise correction in laser doppler forced vibrology of soft products. Biosystems Engin. 99:156-160.

Ding, H., Chin, Y.-W., Kinghorn, A.D. and D'Ambrosio, S.M. 2007. Chemopreventive characteristics of avocado fruit. Sem. Cancer Biol. 17:386-394.

Henrotin, Y. 2008. Avocado/soybean unsaponifiable (ASU) to treat osteoarthritis: a clarification. Osteoarthr. Cartil. 16:1118-1119.

Howarth, M.S., Shmulevich, I., Raithatha, C. and Ioannides, Y. 2003. Online nondestructive avocado firmness assessment based on low mass impact technique. Proceedings V World Avocado Congress (Actas V Congreso Mundial del Aguacate) p.679-685.

Landahl, S., Jeronimidis, G. and Terry, L.A. Unpublished. Final report of Defra (Department for Environment, Food and Rural Affairs; UK) FoodLink project AFM 
235 (CSA/7152/FT1538): Exploitation of non-destructive scanning laser vibrometry for assessment of firmness and damage in fruit and vegetables. 2006-2010.

Landahl, S., Meyer, M.D. and Terry, L.A. 2009. Spatial and temporal analysis of textural and biochemical changes of imported avocado cv. Hass during fruit ripening. J. Agric. Food Chem. 57:7039-7047.

Ledesma, R.L., Frati Munari, A.C., Hernandez Dominguez, B.C., Cervantes Montalvo, S., Hernandez Luna, M.H., Juarez, C. and Moran Lira, S. 1996. Monounsaturated fatty acid (avocado) rich diet for mild hypercholesterolemia. Arch. Med. Res. 27:519-523.

Liu, X., Sievert, J., Arpaia, M.L. and Madore, M.A. 2002. Postulated physiological roles of the seven-carbon sugars, mannoheptulose, and perseitol in avocado. J. Am. Soc. Hortic. Sci. 127:108-114.

Lu, Q., Wang, J., Hernandez Gomez, A. and Garcia Pereira, A. 2009. Evaluation of tomato quality during storage by acoustic impulse response. J. Food Proc. Preserv. 33:356-370.

Meyer, M.D. and Terry, L.A. 2008. Development of a rapid method for the sequential extraction and subsequent quantification of fatty acids and sugars from avocado mesocarp tissue. J. Agric. Food Chem. 56:7439-7445.

Molina-Delgado, D., Alegre, S., Barreiro, P., Valero, C., Ruiz-Altisent, M. and Recasens, I. 2009. Addressing potential sources of variation in several non-destructive techniques for measuring firmness in apples. Biosystems Engin. 104:33-46.

OECD. 2004. Avocados. International Standardisation of Fruit and Vegetables. p.8-31.

Polytec UK Ltd. 2011. Basic principles of Vibrometry. Accessed 09/02/2011. http://www.polytec.com/uk/solutions/vibration-measurement/basic-principles-ofvibrometry.

Róth, E., Berna, A., Beullens, K., Yarramraju, S., Lammertyn, J., Schenk, A. and Nicolaï, B. 2007. Postharvest quality of integrated and organically produced apple fruit. Posth. Biol. Technol. 45:11-19.

Róth, E., Hertog, M.L.A.T.M., Kovaćs, E. and Nicolaï, B. 2008. Modelling the enzymatic softening of apples in relation to cultivar, growing system, picking date and season. International J. Food Sci. Technol. 43:620-628.

Ruiz-Altisent, M., Ruiz-Garcia, L., Moreda, G.P., Lu, R., Hernandez-Sanchez, N., Correa, E.C., Diezma, B., Nicolaï, B. and García-Ramos, J. 2010. Sensors for product characterization and quality of specialty crops - a review. Comp. Electron. Agric. 74:176-194.

Sun, T., Huang, K., Xu, H. and Ying, Y. 2010. Research advances in nondestructive determination of internal quality in watermelon/melon: a review. J. Food Engin. 100:569-577.

Taniwaki, M., Tohro, M. and Sakurai, N. 2010. Measurement of ripening speed and determination of the optimum ripeness of melons by a nondestructive acoustic vibration method. Posth. Biol. Technol. 56:101-103.

Terry, L.A., Chope, G.A. and Giné Bordonaba, J. 2007a. Effect of water deficit irrigation and inoculation with Botrytis cinerea on strawberry (Fragaria $\times$ ananassa) fruit quality. J. Agric. Food Chem. 55:10812-10819.

Terry, L.A., Ilkenhans, T., Poulston, S., Rowsell, L. and Smith, A.W.J. 2007b. Development of new palladium-promoted ethylene scavenger. Postharvest Biol. Technol. 45:214-220. 


\section{Figures}
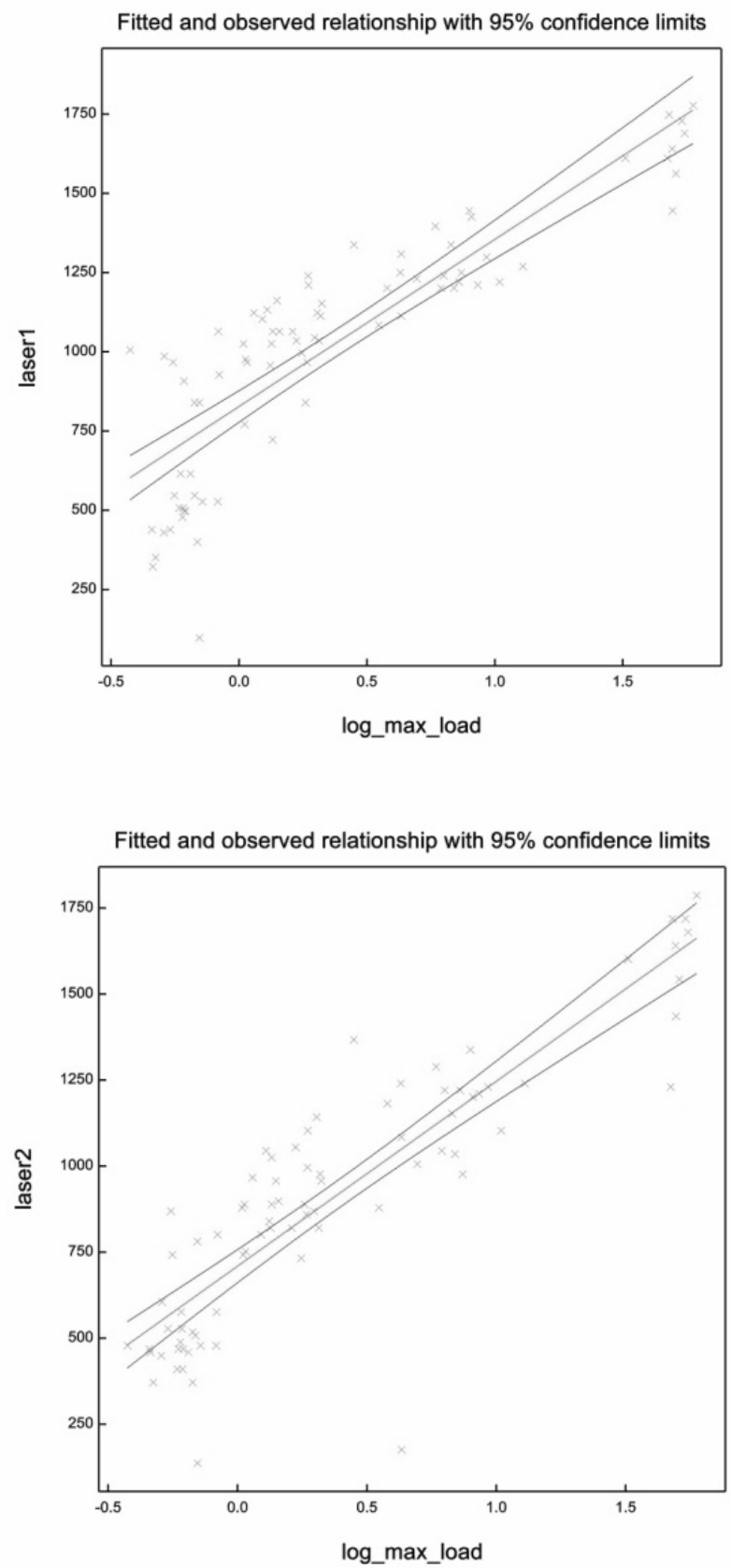

Fig. 1. Simple linear regression plots between resonant frequency $(\mathrm{Hz})$ at seed end (laser $1, \mathrm{r}=0.86$ ) and stem-end (laser 2, r=0.88), and the logarithm (base 10) of the max. load (lbf) measured by means of a uniaxial firmness test. 
